\title{
Complications of central venous catheter insertion in a teaching hospital
}

\author{
Pedro Henrique Comerlato ${ }^{1}$, Taiane Franciel Rebelatto ${ }^{1}$, Felipe Augusto Santiago de Almeida ${ }^{1}$, Luiza Birck Klein², \\ Marcio Manozzo Boniatti ${ }^{3}$, Beatriz D. Schaan ${ }^{2,4}$, Dimitris Varvaki Rados ${ }^{1 *}$ \\ ${ }^{1}$ Internal Medicine Service, Hospital de Clínicas de Porto Alegre (HCPA), Porto Alegre, RS, Brazil \\ ${ }^{2}$ Faculdade de Medicina de Porto Alegre, Universidade Federal do Rio Grande do Sul (FAMED-UFRGS), Porto Alegre, RS, Brazil \\ ${ }^{3}$ Intensive Care Service, HCPA, Porto Alegre, RS, Brazil \\ ${ }^{4}$ Endocrine Division, HCPA, Porto Alegre, RS, Brazil
}

Study conducted at Hospital de Clínicas de Porto Alegre, Porto Alegre, RS, Brazil

Article received: $11 / 22 / 2016$ Accepted for publication: $12 / 19 / 2016$

*Correspondence: Address: Rua Ramiro Barcelos, 2.350, sala 700

Porto Alegre, RS - Brazil Postal code: 90035-903 drados@hcpa.edu.br

http://dx.doi.org/10.1590/1806-9282.63.07.613

\section{SUMmARY}

Introduction: Central venous catheters are fundamental to daily clinical practice. This procedure is mainly performed by residents, often without supervision or structured training.

Objective: To describe the characteristics of central venous catheterization and the complication rate related to it.

Method: Retrospective cohort study. Adult patients undergoing central venous catheter insertion out of the intensive care unit (ICU) of a teaching hospital were selected from March 2014 to February 2015. Data were collected from medical charts using an electronic form. Clinical and laboratory characteristics from patients, procedure characteristics, and mechanical and infectious complications rates were assessed. Patients with and without complications were compared.

Results: Three hundred and eleven (311) central venous catheterizations were evaluated. The main reasons to perform the procedure were lack of peripheral access, chemotherapy and sepsis. There were 20 mechanical complications (6\% of procedures). Arterial puncture was the most common. Procedures performed in the second semester were associated with lower risk of complications (odds ratio 0.35 [95CI 0.12-0.98; $\mathrm{p}=0.037]$ ). Thirty-five (35) catheter-related infection cases $(11.1 \%)$ were reported. They were related to younger patients and procedures performed by residents with more than one year of training. Procedures performed after the first trimester had a lower chance of infection.

Conclusion: These results show that the rate of mechanical complications of central venous puncture in our hospital is similar to the literature, but more attention should be given to infection prevention measures.

Keywords: central venous catheters, catheter-related infections, vascular access devices, pneumothorax, ultrasonography.

\section{INTRODUCTION}

Central venous catheters are fundamental to daily clinical practice. Its main indications are lack of peripheral access, administration of drugs used exclusively in large veins, administration of parenteral diet, and access for hemodialysis. ${ }^{1,2}$ It is estimated that more than 5 million central venous punctures are performed per year in the United States. ${ }^{3}$ Although data from Brazil are scarce, in 2015 the Unified Health System authorized the placement of 95,704 catheters, including short and long-term catheters. ${ }^{4}$
The rate of complications of central venous puncture is estimated at $15 \% .{ }^{1,5}$ Complications related to this procedure are divided into mechanical and infectious. The most common mechanical complications are arterial puncture, hematoma and pneumothorax. Hemothorax, arrhythmia, thoracic duct injury, cardiac tamponade, air embolism or guidewire embolism are more rare but potentially more severe. Using the proper technique for the procedure, a portion of these complications can be avoided. ${ }^{1,5,6}$ Infectious complications (especially catheter-relat- 
ed bloodstream infection), however, besides being potentially serious, are classically associated with high morbidity and mortality and high hospital costs. ${ }^{7}$

The puncture site is one of the determinants of complications, so that pneumothorax is more common in subclavian approaches, whereas arterial puncture is more common for the femoral and jugular veins. ${ }^{1}$ Infectious complications, in turn, appear more common in the femoral and jugular approach. ${ }^{8}$ Other variables may also influence the rate of complications, such as the use of ultrasonography to guide the procedure, the time of the procedure and the amount of training of the professional performing it. ${ }^{1}$

Considering the latter, there is no specific training in most Brazilian teaching hospitals. There are also no national guidelines regarding the professional's qualification for such procedure or protocols to make puncture safer. In addition, the American Board of Internal Medicine ${ }^{9}$ does not provide clear recommendations on the number of procedures to be performed for a physician being trained to be considered qualified, but recognizes that there is a learning curve that varies between individuals and procedures. ${ }^{9}$ It is estimated that $10-20$ punctures are required for the training physician to feel comfortable performing the procedure..$^{10}$ Unfortunately, it is common for such procedures to be learned in an unsystematic manner, taught in the context of medical education based on the "see one, do one, teach one" model. ${ }^{2}$ At the Hospital de Clínicas de Porto Alegre (HCPA), training used to follow this unsystematic model. Despite having a committee for monitoring central venous catheters, most of the learning occurs through observation and supervised performance, with no formal training prior to commencement. Usually, supervision is performed by preceptors of medical residency and more experienced residents (second year or above). After the first few months of training, it is common for procedures to be performed without supervision. The procedures performed by resident physicians of intensive care, on the other hand, are always supervised by preceptors. Considering these problems, the HCPA implemented in 2016 a structured training program for resident physicians focused on central venous puncture techniques outside the intensive care unit and surgical center, with supervised theoretical and practical activities performed on mannequins.

Our study aimed to describe the characteristics of central venous puncture and rate of complications related to this procedure before the implementation of structured training.

\section{Method}

This is a retrospective cohort study that evaluated adult patients undergoing central venous puncture outside the HCPA intensive care unit in 2014. We considered the period from March 2014 to February 2015. The study was approved by the Research and Graduate Group and by the Research Ethics Committee of the HCPA under number 15-0048.

Data were collected through electronic form-based chart reviews. All radiological control exams after central venous puncture were identified by searching the HCPA computerized system. This examination is performed routinely in all patients who undergo jugular or subclavian venipuncture procedure. Patients admitted to the intensive care unit and with peripheral central venous catheter were excluded from the initial sample. Then, a random sample (list of numbers generated randomly by computer program) was selected for evaluation. The description of how patients were included in this evaluation is summarized in Figure 1.

The following information was collected: gender, age, platelet count, prothrombin time, presence of heart disease (ischemic disease, heart failure or valvulopathy) or pulmonary (chronic obstructive pulmonary disease, asthma or interstitial disease), infection, cancer, kidney failure (acute or chronic) and diabetes mellitus on insulin. These comorbidities were noted whenever mentioned in the patient's discharge or death records. The following catheter and procedure data were collected: catheter type (mono and double lumen, dialysis and long stay), indication for insertion of the catheter, area of the professional responsible for the procedure (clinical, surgical or other), training time of the professional placing the catheter (grouped as first-year

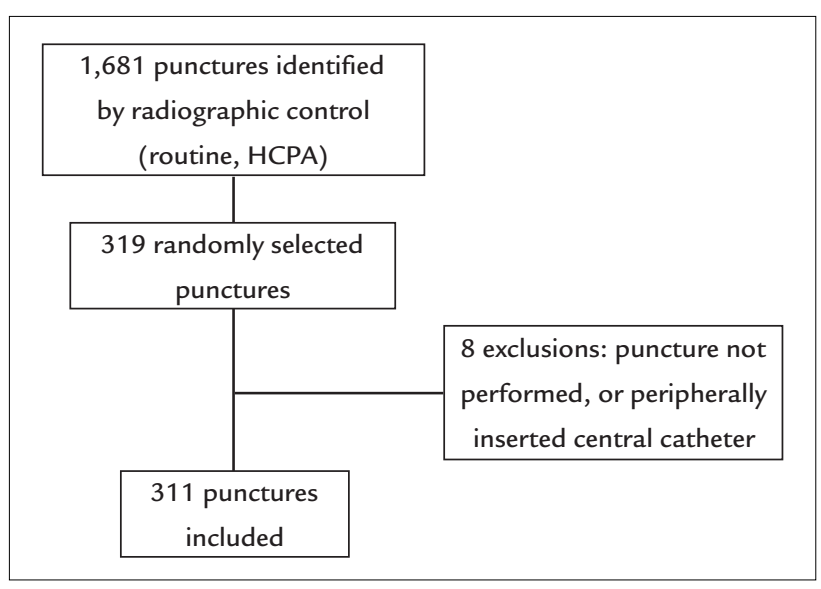

FIGURE 1 Patients flow diagram. HCPA: Hospital de Clínicas de Porto Alegre. 
residents, second-year residents, and third-year or above residents - including in the latter group the hospital's clinical staff - medical staff and professors of medicine), place of the procedure (outpatient surgical center - OSC - or elsewhere), use of ultrasonography and puncture site (jugular or subclavian). Complications related to the procedure were divided into mechanical (arterial puncture, hematoma and pneumothorax) and non-mechanical (catheter-related infection). The data related to the mechanical complications were collected from the systematic review of medical records, with a description of the procedure, radiological examination post-procedure, and subsequent medical and nursing monitoring ( 7 days). The catheter-related infection data were obtained from the Hospital Infection Control Commission, according to the criteria of the Brazilian Sanitary Surveillance Agency (Anvisa): adult patients with a central venous catheter at the time of diagnosis or up to 48 hours after their removal with 1) one or more blood cultures positive for recognized pathogen unrelated to infection elsewhere, or 2) fever, chills, oliguria and/or hypotension together with at least two blood cultures collected on different occasions positive for skin-contaminant pathogens and unrelated to another site of infection. ${ }^{11}$ The incidence of infectious complications was analyzed for the period between insertion of the catheter and hospital discharge or death.

\section{Statistical analysis}

Continuous variables were presented as mean and standard deviation or median and $25-75^{\text {th }}$ percentile (variables with non-Gaussian distribution) and the comparison of outcomes was performed using Student's t-test for repeated measures or a Wilcoxon test for paired data (variables with non-Gaussian distribution). The categorical variables were presented in percentages and absolute numbers and the comparisons were performed using Chi-square test. Differences between groups were assessed by residue analysis. Missing data were excluded from all analyzes. These analyzes were performed in SPSS 20.0 software (SPSS, Chicago, IL). Considering the number of procedures in the HCPA as 1,600 , and the complication rate being $10-15 \%$, the sample was calculated at 175 procedures with $5 \%$ alpha error and power set at $95 \%$.

\section{RESULTS}

A total of 1,681 central venous access punctures were identified in adult patients outside the intensive care unit setting during the residency year of 2014. Of these, 311 were randomly selected for evaluation, with 17 patients undergoing two different punctures and two patients undergoing three different punctures due to the need for more than one access during one or more hospitalizations. It should be noted that none of these patients remained with more than one central access simultaneously.

The characteristics of the patients studied are presented in Table 1. We point out that more than half of the patients were diagnosed with active cancer and a quarter of them were being treated for systemic infection. The main indications for the procedure were lack of peripheral access and need for venous access for chemotherapy and severe sepsis/septic shock. The type of catheter most used was double lumen. In addition, most catheters were placed in the setting recommended by the institution (OSC) and by a professional with up to one year of training.

Mechanical complications occurred in 20 patients, representing $6.5 \%$ of the procedures. Individually, arterial puncture was the most common complication (12 cases), followed by hematoma (nine cases). Two patients had both arterial puncture and hematoma. Only one case of postprocedure pneumothorax was identified, and no chest drainage was required. There were 35 cases of catheter-related infection (11.1\% of the sample). Table 2 presents the characteristics of patients and procedures according to the presence of mechanical complications. In our sample, only thrombocytopenia was associated with an increased risk of complications related to puncture, to the detriment of a higher risk of hematoma, with an odds ratio of 4.9 (95CI 1.27-19.5; $\mathrm{p}=0.02$ ) for patients with thrombocytopenia compared to patients without this condition. Of the variables related to the procedure, only the performance of the procedure in the second semester of the residency year was associated with a lower risk of complications with an odds ratio of 0.35 (95CI 0.12-0.98; $\mathrm{p}=0.037$ ). We emphasize that neither the amount of training of the person responsible for the procedure, time of procedure, and use of ultrasonography were associated with risk of complications. Considering the difference found between the training moments, there was a statistical power of $99 \%$ to detect it.

As for infection related to the catheter, data are presented in Table 3. Patients with a catheter infection were younger (mean age) and had their procedures performed by second-year residents more frequently. It is also worth noting that the procedures performed after the first trimester of the residency year were associated with a lower risk of complications, with odds ratio of 0.69 (95CI 0.51-0.94; $\mathrm{p}=0.002$ ) compared to the procedures performed in the first trimester. For this analysis, the statistical power was also $99 \%$. There was no association between infection rate with catheter type, puncture site, use of ultrasonography or the area of the professional. 
TABLE 1 Patient's characteristics and procedures.

$\mathbf{N}=311$

\begin{tabular}{|c|c|}
\hline Age (years) & $57 \pm 17$ \\
\hline Male & $144 / 311(46 \%)$ \\
\hline INR $>1.5$ & $15 / 165(9.1 \%)$ \\
\hline Platelets $<100,000$ & $41 / 281(14.6 \%)$ \\
\hline Infectious disease & $78 / 311(25 \%)$ \\
\hline Heart disease & $41 / 311(13.1 \%)$ \\
\hline Lung disease & $32 / 311(10.2 \%)$ \\
\hline Cancer & $180 / 311(57.8 \%)$ \\
\hline Kidney disease & $70 / 311(22.5 \%)$ \\
\hline DM on insulin & $34 / 311(10.9 \%)$ \\
\hline Neurological disease with functional limitation & $62 / 311(19.9 \%)$ \\
\hline \multicolumn{2}{|l|}{ Type of catheter } \\
\hline Mono lumen & $88 / 308(28.6 \%)$ \\
\hline Double lumen & $150 / 308(48.7 \%)$ \\
\hline Dialysis & $19 / 308(6.2 \%)$ \\
\hline Long-term catheters & $51 / 308(16.6 \%)$ \\
\hline \multicolumn{2}{|l|}{ Indication for catheter use } \\
\hline Lack of peripheral access & $85 / 268(31.7 \%)$ \\
\hline Sepsis & $66 / 268(24.6 \%)$ \\
\hline Surgery & $23 / 268(8.5 \%)$ \\
\hline Dialysis & $19 / 268(7 \%)$ \\
\hline Chemotherapy & $75 / 268(27.9 \%)$ \\
\hline \multicolumn{2}{|l|}{ Area of professional responsible for the procedure } \\
\hline Clinical & $67 / 298(22.5 \%)$ \\
\hline Surgical & $231 / 298(77.5 \%)$ \\
\hline \multicolumn{2}{|c|}{ Amount of training of professional responsible for the procedure } \\
\hline First-year resident & $219 / 297(73.7 \%)$ \\
\hline Second-year resident & $37 / 297(12.5 \%)$ \\
\hline Third-year resident or above & $41 / 297(13.8 \%)$ \\
\hline \multicolumn{2}{|l|}{ Place where procedure was performed } \\
\hline OSC or surgical unit & $239 / 297(80.5 \%)$ \\
\hline Other & $58 / 297(19.5 \%)$ \\
\hline Use of ultrasound & $99 / 308(32.2 \%)$ \\
\hline \multicolumn{2}{|l|}{ Time of procedure } \\
\hline $8-24 h$ & $282 / 309(91.3 \%)$ \\
\hline $24-8 h$ & $27 / 309(8.7 \%)$ \\
\hline \multicolumn{2}{|l|}{ Puncture site } \\
\hline Right jugular & $145 / 307(46.9 \%)$ \\
\hline Left jugular & $40 / 307(12.9 \%)$ \\
\hline Right subclavian & $111 / 307(35.9 \%)$ \\
\hline Left subclavian & $11 / 307(3.6 \%)$ \\
\hline Catheterization failure & $9 / 300(3 \%)$ \\
\hline Mechanical complication associated with puncture & $20 / 308(6.5 \%)$ \\
\hline Catheter-related infection & $35 / 311(11.2 \%)$ \\
\hline
\end{tabular}

INR: international normalized ratio of prothrombin time; DM: diabetes mellitus; OSC: outpatient surgical center; data presented as mean and standard deviation or total number and percentage. 
TABLE 2 Patient's characteristics and procedures according to the presence of mechanical complications.

\section{Puncture-related complications}

\begin{tabular}{|c|c|c|c|}
\hline & Absent $(n=291)$ & Present $(n=20)$ & $\mathbf{p}$ \\
\hline Age (years) & $57.1 \pm 17.2$ & $55.5 \pm 16.5$ & 0.67 \\
\hline Male & 134/291 (46.2\%) & $8 / 20(40 \%)$ & 0.59 \\
\hline INR $>1.5$ & $14 / 145(9 \%)$ & $1 / 20(12.5 \%)$ & 0.54 \\
\hline Platelets $<100,000$ & $35 / 291(12 \%)$ & $6 / 20(30 \%)$ & 0.04 \\
\hline Infectious disease & $74 / 291(25.4 \%)$ & $4 / 20(20 \%)$ & 0.58 \\
\hline Heart disease & $38 / 291(13 \%)$ & $3 / 20(15 \%)$ & 0.80 \\
\hline Lung disease & $31 / 291(10.6 \%)$ & $1 / 20(5 \%)$ & 0.41 \\
\hline Cancer & 169/291 (58\%) & $11 / 20(55 \%)$ & 0.77 \\
\hline Kidney disease & $67 / 291(23 \%)$ & $3 / 20(15 \%)$ & 0.40 \\
\hline DM on insulin & $32 / 291(10.9 \%)$ & $2 / 20(10 \%)$ & 0.87 \\
\hline Neurological disease & $59 / 284(20.7 \%)$ & $3 / 20(15 \%)$ & 0.50 \\
\hline Professional's area & & & 0.78 \\
\hline Clinical & $62 / 278(22.3 \%)$ & $5 / 20(25 \%)$ & \\
\hline Surgical & $216 / 278(77.7 \%)$ & $15 / 20(75 \%)$ & \\
\hline Amount of training of professional responsible for the procedure & & & 0.93 \\
\hline First-year resident & $204 / 277(73.6 \%)$ & $15 / 20(75 \%)$ & \\
\hline Second-year resident & $35 / 277(12.6 \%)$ & $2 / 20(10 \%)$ & \\
\hline Third-year resident or above & $38 / 277(13.7 \%)$ & $3 / 20(15 \%)$ & \\
\hline Place where procedure was performed & & & 0.17 \\
\hline OSC or surgical unit & $226 / 278(81.3 \%)$ & $13 / 19(68.4 \%)$ & \\
\hline Other & $52 / 278(18.7 \%)$ & $6 / 19(31.6 \%)$ & \\
\hline Use of ultrasound & $91 / 287(31.7 \%)$ & $8 / 20(40 \%)$ & 0.44 \\
\hline Time of procedure & & & 0.56 \\
\hline $8-24 h$ & $261 / 286(91.3 \%)$ & $19 / 20(95 \%)$ & \\
\hline $24-8 \mathrm{~h}$ & $25 / 286(8.7 \%)$ & $1 / 20(5 \%)$ & \\
\hline Puncture site & & & 0.16 \\
\hline Jugular & $170 / 286(59.4 \%)$ & $15 / 20(75 \%)$ & \\
\hline Subclavian & $116 / 286(40.6 \%)$ & $5 / 20(25 \%)$ & \\
\hline Procedures per semester & & & 0.038 \\
\hline First semester & $147 / 288(51 \%)$ & $15 / 20(75 \%)$ & \\
\hline Second semester & $141 / 288(49 \%)$ & $5 / 20(25 \%)$ & \\
\hline
\end{tabular}

INR: international normalized ratio of prothrombin time; DM: diabetes mellitus; OSC: outpatient surgical center; data presented as mean and standard deviation or total number and percentage.

\section{TABLE 3 Patient's characteristics and procedures according to the presence of infectious complications.}

\section{Catheter-related infection}

\begin{tabular}{|c|c|c|c|}
\hline & Absent $(n=276)$ & Present $(n=35)$ & $\mathbf{p}$ \\
\hline Age (years) & $57.7 \pm 16.8$ & $51.5 \pm 18.4$ & 0.044 \\
\hline Male & $129 / 276(46.4 \%)$ & $15 / 276(42.9 \%)$ & 0.69 \\
\hline INR $>1.5$ & $14 / 141(9.9 \%)$ & $1 / 23(4.3 \%)$ & 0.34 \\
\hline Platelets $<100,000$ & $34 / 246(13.8 \%)$ & $7 / 34(20.6 \%)$ & 0.21 \\
\hline Infectious disease & $68 / 276(24.6 \%)$ & $10 / 35(28.6 \%)$ & 0.59 \\
\hline
\end{tabular}


TABLE 3 (cont.) Patient's characteristics and procedures according to the presence of infectious complications.

Catheter-related infection

\begin{tabular}{|c|c|c|c|}
\hline & Absent $(n=276)$ & Present $(n=35)$ & $\mathbf{p}$ \\
\hline Heart disease & $37 / 276(13.4 \%)$ & $4 / 35(11.4 \%)$ & 0.75 \\
\hline Cancer & $164 / 276(59.4 \%)$ & $16 / 35(45.7 \%)$ & 0.13 \\
\hline Lung disease & $27 / 276(9.7 \%)$ & $5 / 35(14.3 \%)$ & 0.40 \\
\hline Kidney disease & $65 / 276(23.5 \%)$ & $5 / 35(14.3 \%)$ & 0.22 \\
\hline DM on insulin & $30 / 276(10.8 \%)$ & $4 / 35(11.4 \%)$ & 0.94 \\
\hline Neurological disease & $53 / 276(19.2 \%)$ & $9 / 35(25.7 \%)$ & 0.40 \\
\hline Professional's area & & & 0.11 \\
\hline Clinical & $56 / 265(21.1 \%)$ & $11 / 33(33.3 \%)$ & \\
\hline Surgical & $209 / 265$ (78.9\%) & $22 / 33(66.7 \%)$ & \\
\hline Amount of training of professional responsible for the procedure & & & 0.012 \\
\hline First-year resident & $201 / 264(76.1 \%)$ & $18 / 33(54.5 \%)$ & \\
\hline Second-year resident & $28 / 264(10.6 \%)$ & $9 / 33(27.3 \%)$ & \\
\hline Third-year resident or above & $35 / 264(13.3 \%)$ & $6 / 33(18.2 \%)$ & \\
\hline Place where procedure was performed & & & 0.65 \\
\hline OSC or surgical unit & $215 / 266(80.8 \%)$ & $24 / 31(77.4 \%)$ & \\
\hline Other & $51 / 266(19.2 \%)$ & $7 / 31(22.6 \%)$ & \\
\hline Use of ultrasound & $86 / 272(31.6 \%)$ & $13 / 35(37.1 \%)$ & 0.51 \\
\hline Time of procedure & & & 0.19 \\
\hline $8-24 h$ & $248 / 274(90.5 \%)$ & $34 / 35(97.1 \%)$ & \\
\hline $24-8 \mathrm{~h}$ & $26 / 274(9.5 \%)$ & $1 / 35(2.9 \%)$ & \\
\hline Puncture site & & & 0.10 \\
\hline Jugular & $160 / 272(58.8 \%)$ & $25 / 35(71.4 \%)$ & \\
\hline Subclavian & $112 / 272(41.2 \%)$ & $10 / 35(28.6 \%)$ & \\
\hline Procedures per trimester & & & 0.026 \\
\hline First trimester & $59 / 276(21.4 \%)$ & $16 / 35(45.7 \%)$ & \\
\hline Second trimester & $83 / 276(30 \%)$ & $5 / 35(14.3 \%)$ & \\
\hline Third trimester & $69 / 276(25 \%)$ & $8 / 35(22.9 \%)$ & \\
\hline Fourth trimester & $65 / 276(23.5 \%)$ & $6 / 35(17.1 \%)$ & \\
\hline Procedures per semester & & & 0.34 \\
\hline First semester & $142 / 276(51.4 \%)$ & $21 / 35(60 \%)$ & \\
\hline Second semester & $134 / 276(48.6 \%)$ & $14 / 35(40 \%)$ & \\
\hline Type of catheter & & & 0.26 \\
\hline Mono lumen & $80 / 209(38.3 \%)$ & $8 / 29(27.6 \%)$ & \\
\hline Double lumen & $129 / 209(61.7 \%)$ & $21 / 29(72.4 \%)$ & \\
\hline
\end{tabular}

INR: international normalized ratio of prothrombin time; DM: diabetes mellitus; OSC: the HCPA outpatient surgical center; data presented as mean and standard deviation or total number and percentage.

To better understand the relation between procedures performed by second year residents and infectious complications, we evaluated the characteristics of the procedures performed by this group. The main indication for central venous puncture was chemotherapy ( 40 vs. $31.2 \%$ for second and first year residents, respectively, $\mathrm{p}<0.001)$. In addition, second-year residents made more punctures earlier that year ( 80.6 vs. $47.9 \%$ of the procedures per- formed in the first semester by residents of the second and first year, respectively, $\mathrm{p}=0.001$ ). There was no difference in relation to comorbidities, platelets or prothrombin time among first and second year residents.

After analyzing the cases in which there was at least one complication, either mechanical or infectious, we identified the subclavian puncture site as a factor associated with less risk of complication, with an odds ratio of 
0.51 (95CI 0.26-0.97; $\mathrm{p}=0.04$ ) compared to the jugular site and procedures performed in the second semester, with odds ratio of 0.53 (95CI 0.28-0.97; $\mathrm{p}=0.04$ ) compared to the procedures performed in the first trimester. There was no association between the rate of grouped complications and the other variables.

\section{Discussion}

Our study showed that the rate of mechanical complications related to central venous puncture is infrequent in our setting. Even without structured training, the incidence of mechanical complications is comparable with data published in the literature. ${ }^{8,9}$ In turn, the rate of catheter infection in our institution is higher than reported in the foreign literature. ${ }^{8,12,13}$

Arterial puncture, hematoma and pneumothorax are, in this order, the most common complications related to central venous punctures according to the literature. . $^{1,8,9}$ We point out in particular the fact that pneumothorax, a complication with greater morbidity, is rare, occurring in less than $1 \%$ of the jugular approaches and up to $1.5 \%$ of the subclavian approaches. ${ }^{1,8,14}$ Puncture site, number of punctures and male gender are factors associated with a greater chance of complications. ${ }^{8,15,16}$ In our study, we observed that the jugular puncture site had a higher rate of mechanical and infectious complications compared to the subclavian vein. The other associations were not observed in our series, perhaps due to the small number of complications identified. The number of punctures could not be obtained from the records in the medical charts, which is an expected limitation when using secondary data. A study ${ }^{16}$ with similar design and heterogeneity of the population (school hospital) demonstrated a rate of mechanical complication approximately three times higher than that found in our study. However, the analysis was performed in an intensive care setting, which may be related to the need for more urgent venous access.

The discrepancy between the rate of central catheter-associated infection identified in the HCPA and in the international literature can be partially explained by different methodologies of data collection and diagnostic criteria for catheter infection. Definitions for central venous catheter-related infection as used in international studies are usually more specific, such as: 1) significant growth of at least one microorganism in catheter-tip culture; 2) 3:1 CFU/mL ratio for the same microorganism of the catheter in relation to the peripheral one; or 3) growth time in the catheter greater than or equal to 2 hours prior to peripheral growth. These criteria are exempted from the definition used by the Brazilian Sanitary Surveil- lance Agency ${ }^{11}$ and are routinely adopted by institutions in the country. Compared to other studies conducted in Brazil, we found higher rates of infection. ${ }^{17,18}$ However, the comparison is limited because these studies were performed in specific populations (e.g., chemotherapy, dialysis), and some of them were related to long-term catheters. We did not find Brazilian studies with heterogeneous population samples similar to ours.

Current, unstructured training may partly explain the higher incidence of infectious complications compared to mechanical ones. The training focuses on the puncture, i.e., vessel location and catheter insertion. The infection prevention bundle, ${ }^{19}$ including hand hygiene, use of a maximum precautionary barrier during insertion, and daily checking of the need for catheter maintenance, for example, is not part of the training.

The results show that the rate of puncture complications identified in the HCPA is comparable with data from other centers. In addition, we have an indirect finding that unstructured training is capable of promoting a reasonable learning curve for resident physicians, with a reduction in the rate of events (mechanical and infectious) after the first few months of training. This finding may appear to be in disagreement with the absence of a relation between complication rate and the amount of training performed by the person performing the puncture. However, more experienced physicians performed fewer procedures (especially in the second semester) and it is possible that these procedures involved greater technical difficulty and, therefore, did not represent the same group of patients and/or procedures. Second-year residents performed more punctures in patients requiring access to chemotherapy, that is, patients who were immunosuppressed and more susceptible to infections. This finding may partially explain the higher infection rate in the procedures performed by second-year residents and reinforces the impression that these are procedures performed in more severe patients, indicating reverse causality as a probable reason for this result.

Limitations of our study include retrospective design, which may hinder recovery of outcomes and related factors due to underreporting in the medical record. Another limitation is that the study is observational, therefore we cannot exclude the hypothesis that differences may be due to overlooked confounding variables. The low prevalence of procedures performed by more experienced professionals may limit some findings. Finally, failure to evaluate femoral vein procedures partially limits the generalization of our results. As future perspectives, this project also aims to evaluate the effectiveness of the struc- 
tured training that will soon be implemented in the HCPA. Considering the low event rate found, confirmation of these findings in a larger sample would also be interesting.

\section{Conclusion}

The analysis of the results of the current training practice demonstrates a rate of mechanical complications similar to the data available in the literature. However, our rates of catheter infection appear to be higher than expected. Our results suggest that structured training should focus not only on the technique of vessel location and catheter insertion but also on the bundle of infection prevention measures.

\section{Resumo}

Complicações de punções venosas centrais em um hospital de ensino

Introdução: Cateteres venosos centrais são fundamentais na prática clínica diária. Em hospitais de ensino, esse procedimento é realizado por médicos residentes, frequentemente sem supervisão ou treinamento estruturado.

Objetivo: Descrever as características das punções venosas centrais e a taxa de complicações relacionadas.

Método: Estudo de coorte retrospectiva. Foram selecionados pacientes adultos submetidos a punção venosa central fora de unidade de terapia intensiva (UTI) de um hospital de ensino no ano letivo de 2014 (março de 2014 a fevereiro de 2015). Os dados foram coletados por meio de revisão de prontuários com o uso de formulário eletrônico. Foram avaliadas características clínicas e laboratoriais dos pacientes, características do procedimento, taxa de complicações mecânicas e infecciosas relacionadas. Foram comparados os pacientes com complicações em relação àqueles sem complicações.

Resultados: Foram avaliadas 311 punções venosas centrais. Os principais motivos para realização do procedimento foram falta de rede periférica, quimioterapia e sepse. Ocorreram 20 complicações mecânicas (6\% dos procedimentos); punção arterial foi a mais comum. Procedimentos realizados no segundo semestre do ano letivo foram associados a menor risco de complicações (razão de chances de 0,35 [IC95 0,12-0,98; $p=0,037$ ]). Foram descritos 35 casos de infecção relacionada ao cateter $(11,1 \%)$. Casos de infecção foram associados a pacientes mais jovens e procedimentos realizados por residentes com mais de um ano de treinamento. Procedimentos realizados após o primeiro trimestre tiveram menor chance de infecção.
Conclusão: Esses resultados mostram que a taxa de complicações mecânicas de punção venosa central em nosso hospital é semelhante à da literatura; porém, maior atenção deve ser dada para medidas de prevenção de infecção.

Palavras-chave: cateteres venosos centrais, infecções relacionadas a cateter, dispositivos de acesso vascular, pneumotórax, ultrassonografia.

\section{References}

1. McGee DC, Gould MK. Preventing complications of central venous catheterization (Review). N Engl J Med. 2003; 348(12):1123-33.

2. Moureau N, Lamperti M, Kelly LJ, Dawson R, Elbarbary M, van Boxtel AJ, et al. Evidence-based consensus on the insertion of central venous access devices: definition of minimal requirements for training. Br J Anaesth. 2013; 110(3):347-56

3. Raad I. Intravascular-catheter-related infections. Lancet. 1998; 351(9106): 893-8.

4. Ministério da Saúde / DATASUS. Informações de Saúde - Dados detalhados das AIH [cited 2016 Jun 1]. Available from: http://tabnet.datasus.gov.br.

5. Smith RN, Nolan JP. Central venous catheters. BMJ. 2013; 347:f6570.

6. Tukey MH, Wiener RS. The impact of a medical procedure service on patient safety, procedure quality and resident training opportunities. J Gen Intern Med. 2014; 29(3):485-90

7. Rivard PE, Luther SL, Christiansen CL, Shibei Zhao, Loveland S, Elixhauser A, et al. Using patient safety indicators to estimate the impact of potential adverse events on outcomes. Med Care Res Rev. 2008; 65(1):67-87.

8. Parienti JJ, Mongardon N, Mégarbane B, Mira JP, Kalfon P, Gros A, et al. Intravascular complications of central venous catheterization by insertion site. N Engl J Med. 2015; 373(13):1220-9.

9. Eisen LA, Narasimhan M, Berger JS, Mayo PH, Rosen MJ, Schneider RF. Mechanical complications of central venous catheters. J Intensive Care Med. 2006; 21(1):40-6.

10. Hicks CM, Gonzalez R, Morton MT, Gibbons RV, Wigton RS, Anderson RJ. Procedural experience and comfort level in internal medicine trainees. J Gen Intern Med. 2000; 15(10):716-22.

11. Agência Nacional de Vigilância Sanitária - Ministério da Saúde. Critérios diagnósticos de infecções relacionadas à assistência à saúde. Brasília: Agência Nacional de Vigilância Sanitária; 2013. p. 43-45.

12. Maki DG, Kluger DM, Crnich CJ. The risk of bloodstream infection in adults with different intravascular devices: a systematic review of 200 published prospective studies. Mayo Clin Proc. 2006; 81(9):1159-71.

13. Lorente L, Villegas J, Martín MM, Jiménez A, Mora ML. Catheter-related infection in critically ill patients. Intensive Care Med. 2004; 30(8):1681-4.

14. Evans LV, Dodge KL, Shah TD, Kaplan LJ, Siegel MD, Moore CL, et al. Simulation training in central venous catheter insertion: improved performance in clinical practice. Acad Med. 2010; 85(9):1462-9.

15. Berwick DM. Developing and testing changes in delivery of care. Ann Intern Med. 1998; 128(8):651-6.

16. Calvache JA, Rodríguez MV, Trochez A, Klimek M, Stolker RJ, Lesaffre E. Incidence of mechanical complications of central venous catheterization using landmark technique: do not try more than 3 times. J Intensive Care Med. 2016; 31(6):397-402.

17. Freire MP, Pierrotti LC, Zerati AE, Araújo PH, Motta-Leal-Filho JM, Duarte LP, et al. Infection related to implantable central venous access devices in cancer patients: epidemiology and risk factors. Infect Control Hosp Epidemiol. 2013; 34(7):671-7.

18. Marcondes CRR, Biojone CR, Cherri J, Moryia T, Piccinato CE. Complicações precoces e tardias em acesso venoso central. Análise de 66 implantes. Acta Cir Bras. 2000; 15(Suppl 2):73-5.

19. Pronovost P, Neddham D, BerenholtD, Chu H, Cosgrove S, Sexton B, et al. An intervention to decrease cateter-related bloodstream infections in the ICU. N Engl J Med. 2006; 355(26):2725-32. 